\title{
Del jazz al rap. De la reproducción mecánica a la reproducción digital de la música negra norteamericana
}

Igael González Sánchez

Universidad Pedagógica Nacional, Unidad Tijuana, Tijuana, México igael.gonzalez@gmail.com

Recepción: septiembre 2020. Aceptación: diciembre 2020.

\section{Resumen}

Este trabajo explora el paso de la reproducción mecánica a la era de la reproducción digital, en el ámbito especifico de la música popular norteamericana. Se retoman conceptos y algunas reflexiones iniciadas en la Escuela de Frankfurt por Theodor W. Adorno y Walter Benjamin, particularmente aquellas sobre la industria de la música. Estas se establecen como punto de partida y como marco interpretativo, a partir de los nexos entre las manifestaciones musicales y el cambio tecnológico y estructural. La música popular norteamericana (particularmente el jazz y el rap) y la industria discográfica que se edifica en torno a ella brindan uno de los mejores ejemplos sobre la incorporación de la música afronorteamericana a la llamada era de la reproducción mecánica y, con la emergencia del rap, a la música reproducida digitalmente.

Palabras clave: sociología de la música, jazz, rap, industria musical, música afroamericana

\section{Do jazz ao rap. Da reprodução mecânica à reprodução digital da música negra na América do Norte}

\section{Resumo}

Este trabalho explora a passagem da reprodução mecânica para a era da reprodução digital, no campo específico da música popular norte-americana. São retomados conceitos e algumas reflexões iniciadas na Escola de Frankfurt por Theodor W. Adorno e Walter Benjamin, em particular sobre 
a indústria musical. Estas são estabelecidas como ponto de partida e como quadro interpretativo, a partir de articulações entre as manifestações musicais e a mudança tecnológica e estrutural. A música popular norteamericana (particularmente o jazz e o rap) e a indústria fonográfica que se constrói em torno dela fornecem um dos melhores exemplos da incorporação da música africana- americana na chamada era da reprodução mecânica e, com o surgimento do rap, na música digitalmente reproduzida.

Palavras-chave: sociologia da música, jazz, rap, indústria musical, música africana-americana

\title{
From Jazz to Rap. From Mechanical to Digital Reproduction of American Black Music
}

\begin{abstract}
This paper explores the shift from the mechanical reproduction to the digital reproduction era, specifically in North-American popular music. The paper relies on concepts and ideas from the Frankfurt School, specifically from Theodor W. Adorno and Walter Benjamin's works on the music industry. By using their ideas as a starting point and as an interpretative framework, the nexus between musical manifestations is discussed, as well as technological and structural change. American popular music (specifically jazz and rap) and the record industry that emerged around it, are used as a good example of the incorporation of African American music to mechanical reproduction, and with the emergence of rap, of the shift to the era of digitally reproduced music.
\end{abstract}

Keywords: Sociology of music, jazz, rap, music industry, African American music

A Carlos Ramón, mi padre.

\section{Introducción}

Con el dejo de nostalgia con que se estudia y se enseña la tradición teórica de la llamada Escuela de Frankfurt, y advirtiendo cual profecías algunas de sus conjeturas sobre el devenir de las industrias culturales en el capitalismo actual, es fácil advertir por qué Theodor Adorno lamentase la extinción del "buen oyente" -aquel que "comprende la música como su 
propia lengua sin preocupación de la gramática"- ${ }^{1}$ cuya exigencia está contenida en el auténtico acto de escuchar. En efecto, pareciese que entre más avanza la modernidad, las audiencias musicales se convierten en enormes pero diferenciadas masas anónimas identificadas en un gusto común por algún artista emblemático del género de predilección. El oyente común, dice Adorno "se transforma en un comprador que todo lo acepta... [que] no opera de manera crítica con respecto al todo preconcebido sino que suspende la crítica que la totalidad de estética congruente ejerce sobre los aspectos quebradizos de la sociedad" (Adorno, 2009, p. 19).

Si tomamos como punto de partida las ideas de Theodor Adorno (19031969) y Walter Benjamin (1892-1940) en torno a la industria cultural, la música popular y la reproducción masiva del arte tienen bastante que decir del fenómeno de la mercantilización del jazz y del rap. Se trata de géneros musicales que de manera importante han influido en el desarrollo de la industria disquera norteamericana. Ambas manifestaciones generaron una industria cultural cuya base se estructura a partir de la explotación de las novedades creativas del pueblo y en la venta de un producto musical.

Llevar al ámbito de la reflexión el jazz o rap se trata de una cuestión de gusto y no hay demasiada pretensión en esta elección. A fin de cuentas, el gusto personal siempre tiene bases y criterios sociales, según sostiene Bourdieu (2000) y el hecho de que exista toda una industria musical edificada en torno a estos géneros no cambiará tal situación. Tengamos en cuenta que en cualquier ciudad del mundo más de una estación de radio dedica su frecuencia a transmitir, día y noche, jazz y rap. No hace falta mencionar otras tantas formas de difusión por internet. Por otro lado, cada época y cada contexto produce sus formas musicales específicas, por ello debemos tomar en consideración formas musicales histórica y culturalmente determinadas en torno a las cuales se construye un entablado de relaciones de diversa índole, con distintos grados de participación en la cadena de valor que la música genera como actividad socioeconómica.

En los apartados que componen este ensayo toman en consideración las modificaciones tecnológicas, las técnicas de producción, reproducción y transmisión de la música y como estas van de la mano con una evolución

\footnotetext{
${ }^{1}$ Keith Negus (1997) considera que los seis tipos ideales de oyente representan la mayor sistematización lograda por Adorno. Estos son: experto o profesional (directores, compositores, músicos de oficio), buen oyente (comprende la música como si fuera su propia lengua sin preocupación de la gramática), oyente consumidor (constantemente informado y coleccionista), oyente emotivo ("más sincero que el anterior", deliberadamente desinformado, el conocimiento atenta contra la verdadera emoción), oyente resentido (clásico pre burgués o el fan del jazz ignorante de las evoluciones estilísticas) y oyente pasatista.
} 
ideológica de creación musical. Se intentó retomar la línea trazada por la escuela crítica del materialismo histórico para hablar de nuevas formas y nuevas manifestaciones musicales populares cuyos contenidos digitales circulan a través de la red. Hemos ingresado de lleno a la economía digital caracterizada por la circulación de inmensurables cantidades de información y una convivencia estructurada desde redes sociales e identidades construidas online. Vivimos la era de la reproducción digital y en contextos esquizofónicos. ${ }^{2}$ Somos habitantes de un contexto globalizado donde la producción de formas musicales y la experiencia de la escucha se han modificado sustancialmente. Las tecnologías de las últimas tres décadas han incidido en la experiencia de todos, y no sólo en la de los músicos o los aficionados de éste o aquel tipo de música (Yúdice, 2007, p. 17). La música misma avisa del "avenimiento de un nuevo orden", viene a anunciar "una sociedad del signo, y de las relaciones sociales unificadas en el dinero" (Attali, 1995, p. 18). La producción musical en el capitalismo tardío nos plantea el disfrute inmaterial convertido en mercancía y el advenimiento de relaciones sociales de producción virtuales.

Evidentemente, hay un margen temporal demasiado amplio entre la consolidación comercial de estas dos manifestaciones musicales afroamericanas. Nuestra reflexión no obedece a un planteamiento sincrónico. Por ello advertimos que nuestra unidad de análisis se encuentra en las relaciones sociales de producción de la industria musical erigida en torno al jazz y al rap y los planteamientos frankfurtianos sobre la obra del arte en la era de la reproducción mecánica el eje interpretativo.

Como resultado de este ejercicio analítico llegamos a la conclusión que, al paso del tiempo, la creatividad y la innovación en música va de la mano al éxito comercial; la sucesión constante de estilos musicales genera sentido en tanto un bien de consumo en torno al cual se identifica una generación; pero como cualquier otra manifestación inserta en la cultura mediática al poco tiempo morfa en otro tipo de consumo bajo otros fines expresivos.

En su fatal diagnóstico, Adorno apenas consideró que la música popular es un singular vehículo de comunicación de ideas y sentimientos, sino que deviene tal a partir de un condicionamiento estético y un deseo colectivo que se convierte en comportamiento de mercado (Adorno, 2009, p. 20). Dicho lo anterior, no será difícil llegar a la conclusión de que los usos y

\footnotetext{
${ }^{2}$ Schizophonia o esquizofonia refiere al desborde de la fuente original por parte de la copia. Este término, similar al "aura" benjaminiano, permite enfocar críticamente "no sólo el proceso de desborde sino también el consecuente estado de la copia y la contestación a de su autenticidad" (Feld, 1994, p. 260). Traducción del autor.
} 
funciones sociales de la música han cambiado en la misma medida que cambian los medios, ya sea "mecánicos" o "digitales" para su propagación. Los productos musicales que se asumen comerciales son, independientemente de sus usos liberadores, una mercancía fetichizada, reificada, con el poder de inducir al oyente a un estado alienante. El jazz tuvo como soporte de propagación el disco de vinilo; el rap usó el vinilo como fuente sonora de su creación. Así, el sample, la materia prima por excelencia para el rap, se divulgó inicialmente por medio de casetes. Sus artistas vivieron la transición a la era digital con el disco compacto (CD). Los creadores del rap llevaron el lenguaje musical africano al límite de la alta tecnología, ${ }^{3}$ y las decisiones que han tomado y el rumbo que han seguido sus impulsos creativos hacen eco de "las prioridades musicales de la diáspora africana" [junto] con "las prioridades culturales negras" en la era de la reproducción digital (McLaren, 1998, p. 161). La música tiene cada vez menos un soporte físico Consideremos que hoy en día el consumo musical se realiza a partir de internet, que ya no se usa el CD, y que los vinilos (a pesar de su supuesto revival) si siguen siendo utilizados es porque representan para el Disc Jockey (DJ) lo mismo que un instrumento para un músico.

\section{El legado frankfurtiano}

La perspectiva analítica de Adorno y Benjamin coinciden de forma notable, aun cuando ambos tenían un interés mayor en el análisis estético, en la música y las artes en general, antes que en la teoría social. Sus aportes han permitido constituir a estos en objetos de análisis científico. Siendo partidarios del materialismo dialéctico subrayaron la necesidad de poner atención a las relaciones estructurales y superestructurales de producción en la sociedad capitalista (Rojas Crotte, 1999). La epistemología subyacente en tal principio tiene como punto de partida la existencia de la sociedad, en tanto se constituye como una realidad que surge "entre posibilidades históricas que están determinadas por el nivel heredado de cultura material e intelectual", esto es, que se puede sostener que la gama de posibles futuros que enfrenta una sociedad están vinculados directamente a sus legados culturales, materiales e intelectuales (Alexander, 1989, p. 210). Al mismo tiempo, las necesidades tecnológicas determinan la organización

\footnotetext{
${ }^{3}$ Según Kofi Agawu (1995), el "ritmo africano" es un invento de la década de 1950 en tanto la "música Africana” se interpretó como un fenómeno esencialmente rítmico. Es fácil ver que una ideología predominante de diferencia entre "África" y "Occidente" subyace a esa idea. Aunque las rítmicas procedentes del continente negro caracterizan por aspectos mecánicos (agrupación, acentos, periodicidad) y patrones más amplios de significación temporal (movimiento, lenguaje y gesto). El rap como género musical retoma y revalora el uso del cuerpo y la voz como fenómenos rítmicos del lenguaje.
} 
económica, debido a que brindan las metas de la vida política sus discursos legitimadores, al mismo tiempo que determinan la forma y el contenido de la vida social, las fuerzas de producción (o sea los elementos económicos y tecnológicos) operan como los factores condicionantes de las relaciones sociales. estableciendo "las reglas legales", especialmente las "leyes de propiedad privada que brindaban el contenido para que operen las fuerzas económicas" (Giner, 2008).

Dado el poder de la tecnología, todas las diferenciaciones de la sociedad anterior se han desmoronado. Sólo hay un sistema omnipresente una sociedad unidimensional y un hombre unidimensional (Marcuse, 1968). De esta forma, la cultura y el arte pueden comprenderse, en este plano conceptual, como un producto más de necesidades tecnológicas o bien como resultado de la adaptación a las mismas. El término cultura expresa la implicación de la mente en el proceso histórico de la sociedad: significa la totalidad de la vida social en una situación dada, tanto en lo relacionado a reproducción ideacional (en lo que refiere a la cultura en el sentido más amplio del término o bien al 'mundo espiritual') y su reproducción material ('civilización') en tanto conforman una unidad comprensible y distinguible históricamente (Marcuse, 1968).

A Theodor W. Adorno se le reconoce por sus contribuciones en envergadura filosófica sobre el carácter fetichista de la música, y por ser un crítico recalcitrante de las expresiones de la música popular de masas derivada de la industria cultural; Walter Benjamin es identificado por ser quien abrió el camino de la crítica artística, cultural y literaria en el marxismo, señalando que el arte no es un producto autónomo de la experiencia humana, sino que forma parte de la socialización masiva en la época de la reproductibilidad mecánica (Giner, 2008).

Tanto Adorno como Benjamin hacen de la trascendencia su punto de partida, ${ }^{4}$ y evidentemente tenemos como resultado una producción intelectual asociada estrechamente a una teoría social militante. Ante tal escenario, queda al intelectual crítico la tarea de observar y articular conceptualmente la verdad que la obra de arte expresa sensorialmente. 0 que (al menos) condene la teoría meramente explicativa e inherentemente conservadora. ${ }^{5}$ Aunque algunas de las afirmaciones adornianas

\footnotetext{
${ }^{4}$ Las teorías trascendentes trabajan con una noción de razón crítica y las teorías positivas con un empobrecido concepto de razón técnica (Alexander, 1989, p. 212).

${ }^{5}$ Encarnada en la figura de Talcott Parsons y en otros pensadores y sociólogos liberales que dominaban la academia norteamericana durante el período de exilio frankfurtiano. Sus críticas agudas de la sociedad occidental contemporánea sin duda influyeron a los movimientos estudiantiles de los años
} 
sobre la sociedad contemporánea y los medios de control parecerían un tanto descabelladas, pero no menos ciertas en el siglo XXI. Adorno sostenía, por ejemplo, que la música popular permitía obtener "el placer del instante" convertido en el pretexto para dispensar al oyente de pensar y con ello evitar el acto del auténtico escuchar; que vivimos en un mundo atrapado por la burocracia, la administración tecnocrática. En tal cautiverio el individuo como tal es cosa del pasado: la era de la concentración del capital, la razón instrumental y la cultura de masas ha destruido cualquier posibilidad de libertad personal; que ha desaparecido la capacidad crítica del pensamiento. Ante tal situación opresiva se objetiviza y naturaliza la imposibilidad de cambiar el estado de las cosas; que la industria cultural es el filtro a través del cual muchos de estos procesos se vuelven posibles (Bottomore, 1983).

\section{Música e industria cultural}

La industria cultural designa el campo de las tecnologías comunicacionales y mediáticas. Las llamadas "industrias sin chimeneas" es el término con el que Adorno y Benjamin hacen alusión a espacios donde de forma altamente racionalizada se fabrican productos artísticos y culturales en serie. Para ellos las artes no son independientes de la industria y del comercio. Más bien, estos objetos son elaborados de una forma análoga a la producción de bienes por parte de industrias que desarrollaron sus métodos de manufactura para producir bienes de consumo en enormes cantidades para su distribución masiva y que requieren de una "línea de ensamblaje". Dicho de otro modo, la industria cultural es la metáfora usada para señalar que los productos artísticos fueron producidos de acuerdo a la misma racionalidad y procedimientos organizacionales del capitalismo con el objetivo de obtener beneficios.

Walter Benjamin atendió el asunto de la producción artística de manera particular: propuso la noción del "aura" como característica inmanente a las obras de arte. En este sentido, el carácter áureo de una obra humana consiste en "el carácter irrepetible y perenne de su unicidad o singularidad". La obra de arte aurática, sólo puede ser una obra auténtica cuando no admite copia alguna de sí mismo. Toda reproducción de ella es una profanación (Benjamin, 2003, p. 16). Tal carácter proviene del hecho de que lo valioso que en ella reside tuvo lugar en un momento único: aconteció una

60, en la misma medida en que sus escritos se consideraron una feroz denuncia contra las "consecuencias paralizantes de la represión exigida por la sociedad capitalista” (Alexander, 1989, p. 213). 
epifanía o revelación de lo sobrenatural que perdura metonímicamente en ella. Según Benjamin, en esta época de reproductibilidad técnica, cualquier obra artística (o aquel objeto que reciba este adjetivo) como tal, aún no siendo hecha para ser reproducida existe bajo el modo de la reproducción en tanto se involucra en relaciones sociales de producción.

Ahora bien, tomando específicamente la obra de arte musical, podrá objetarse que de alguna manera preexiste guardada en la memoria del músico o en las notaciones de una partitura Está ahí en infinitas versiones o actualizaciones diferentes y es, sin embargo, en cada caso, siempre única al ser interpretada. Pasa a existir, realmente todas y cada una de las veces que es ejecutada por algún intérprete. Sin embargo, hasta antes de la aparición de los aparatos de grabación, la música se ejecutaba ante todo para exhibirse. Era sometida a prueba ante un público dispuesto a entregarse a la experiencia estética. con la aparición de los medios de reproducción las expresiones musicales populares, han sido colonizadas y absorbidas por la industria cultural.

Según Adorno, "el cambio de función de la música afecta los elementos constitutivos de la relación entre arte y sociedad; cuando más inexorable es el principio del valor de cambio a los hombres en torno a los valores de consumo, tanto más se enmascara el valor de cambio mismo, como objeto de placer" (Adorno, 2009, p. 26). En este sentido, las expresiones colonizadas forman parte del desarrollo de productos que se identifican como "cultura de masas". Tales productos, dado su carácter masivo y mediático, juegan un enorme papel en la dominación de los pueblos. ${ }^{6}$

La reproductibilidad masiva no se ha convertido para el arte en una ley formal inmanente [...] la industrialización radical del arte, su adaptación total a los estándares técnicos alcanzados, colisiona con lo que en el arte se opone a la integración. Si la técnica tiende al punto de fuga de la industrialización, estéticamente esto sigue sucediendo a costa de la elaboración inmanente y por tanto de la técnica misma (Adorno, 2004, p. 357).

El desarrollo tecnológico vinculado a las industrias culturales termina imponiendo las reproducciones artísticas en la cotidianidad, de la misma forma que los productos estandarizados, fabricados en serie, satisfacen

${ }^{6}$ Convendría considerar las formas de dominación a través de la ideología, la alienación o reificación operando a través del fetichismo de la mercancía. No pueden dejarse de lado las ideas de Wilhelm Reich (1973), también identificado con la escuela crítica, sobre la psicología de masas del fascismo. 
necesidades de amplios sectores de la población en innumerables lugares (Mattelart, 1974). En términos de Adorno, "el papel de la música en el proceso social es exclusivamente el de una mercancía; su valor es el del mercado [...] su valor de uso se ha subsumido completamente en su valor de cambio" (Adorno, 2008). En la crítica frankfurtiana a los productos de la industria cultural se señala que cuando estos son consumidos, no hay espacio para la imaginación o la reflexión por parte de las audiencias. En otras palabras, no es la canción lo que se ha degradado, sino la presencia de la canción degradada en nuestro medio lo que ha aumentado (Attali, 1995).

\section{Producir los gustos populares}

El término música popular se emplea desde fines del siglo XIX y principios del siglo XX para designar a aquella música que se desarrolló con la industrialización desde mediados del siglo XIX. En tanto producto estético, su composición obedece a los gustos e intereses de las clases medias urbanas de la época. Por añadidura, es música comprensible y ejecutable por la mayoría de la población. Su apreciación no requiere gran conocimiento ni de teoría ni de técnicas musicales; comprende piezas cortas con líneas melódicas y acompañamiento armónico sencillo.

De forma paralela a Adorno y a Benjamin, otros investigadores en la década de 1930 establecieron una tajante distinción entre la música tradicional y la música popular. Por ejemplo, Béla Bártok, compositor y folklorista húngaro, consideraba dos tipos de música popular: la "música culta popularesca" [o "música popular ciudadana"] y la "música popular de las aldeas" [la música "campesina”]" (Bártok, 1997, p. 66). ${ }^{7}$ Ahora bien, desde la óptica crítica la música popular refiere a la música del gusto medio (y no al género musical conocido como música pop). Pero sobre todo, se refieren a música producida masivamente y difundida mediáticamente; explotada como tranquilizante y distractor; convertida en factor imprescindible de la convivencia cotidiana en la modernidad. Un medio de expresión e integración favorito de los movimientos y modas juveniles al mismo tiempo; o bien, uno de los mecanismos utilizados por los aparatos gubernamentales para incluir en un dispositivo ritual totalizante las prácticas populares.

\footnotetext{
${ }^{7}$ Bártok, etnomusicólogo y compositor húngaro vinculado al nacionalismo folklórico europeo, sostenía que la música popularesca "hace alusión a aquellas melodías de estructura más bien simple, compuesta por autores diletantes, pertenecientes a la clase burguesa” (Bártok, 1997, p. 66). Mientras que, según Bártok, la música campesina en sentido estricto consiste en una masa de melodías de carácter y estructuras iguales.
} 
Adorno tendía a desaprobar la música popular. Pensaba que apartar la música del espectáculo visual que la acompañaba era a veces positivo, en tanto permitía apreciar la música con más objetividad. Esto sería dejar pasar por alto la ejecución de instrumentos, los que anteriormente se tañían para poder tener música. Y la ejecución de instrumentos sobre todo los instrumentos de orquesta que requieren mayor estudio al igual que sus repertorios, brindan un espacio social (o campo) para la distinción de clase (cfr. Bourdieu, 2003). La música necesitaba ser negativamente crítica, "no ser un elemento de complacencia para el auditorio; pero tampoco, bajo la apariencia de innovación, encubrir los conceptos reificadores" (Rojas Crotte, 1999, p. 80).

El continuo desarrollo técnico de las industrias culturales tiene como audible consecuencia la expansión cuantitativa de la música grabada. La consecuencia no deseada de tal efecto resulta en el empobrecimiento auditivo de la sonoridad. En comparación con la generación anterior es el poder de la tecnología, y las consecuencias culturales de esta tecnología que permite otra forma de comprender el escuchar música. Como varios elementos alrededor de la misma, tales como la producción, la creación, el performance en vivo, la reproducción a elección. "La conciencia de la masa de oyentes es adecuada a la música hecha fetiche. Se escucha bajo la prescripción y evidentemente, la perversión en si no sería posible si se opusiera resistencia; si los oyentes fuesen capaces de algún modo de ir en sus exigencias más allá del perímetro del ofertado" (Adorno, 2009, p. 35).

Dado el carácter masivo, el acento urbano y la finalidad mercantil que la música popular adquiere en el contexto actual, esta se erige como pilar de las "industrias sin chimeneas" en tanto factor productivo de las sociedades tardo-capitalistas. "No por azar surgió el sistema de la industria cultural en los países industriales más liberales, así como es en ellos donde han triunfado todos sus medios característicos: el cine, la radio, el jazz y los magazines" (Horkheimer y Adorno, 1988, p. 7). Evidentemente para la emergencia de este tipo de músicas fue necesario la existencia de técnicas de registro, reproducción y difusión masiva del sonido. A partir de1948 surgió la tecnología del disco de vinilo o Long Play (LP) que difundió música producida en serie a partir de centros de producción dominados por al industria disquera norteamericana y europea (RCA, BMG, Warner). Este tipo de música, sin la necesidad de pretender ser arte llega a amplios sectores pasivos y alienados, de gusto moldeable. Esto es, cuando la música se inserta en los medios de comunicación masiva, particularmente la radio (hoy en día incluyendo la radio por Internet), la función social de la música se modifica hacia espacios de cooperación sónica con el todo social. 
Esto resulta más evidente cuando se escucha la programación musical en espacios colectivos tales como fondas, los talleres mecánicos, o como oyente involuntario de las preferencias de los chóferes en los trayectos del transporte público. La programación de la radio comercial cumpliría hasta cierto punto con tal finalidad, ya que en nuestra cotidianidad experimentamos los éxitos de la música popular como ruido de fondo. Hoy en día las emisoras del cuadrante se dedican a un género específico de música (i.e. "radioamor", "radiolatina", etc.). Según Benjamin la efectividad radiofónica "radica en que la música que emite un programa sea considerada como auténtica por los oyentes [...] sea por subvertir la lógica comercial, sea por reflejar auténticamente algo, las emisoras apelan al oyente que vive afectiva e inconscientemente lo que escucha como algo auténtico, como un aquí y ahora único e irrepetible. La reificación aurática -en tanto fin último del modo de producción de la industria cultural-se retira en ciertos momentos de la recepción radiofónica" (Sammartino, 2008).

Ahora bien, ¿con qué materia prima se hace la música hoy por hoy? Hacerla con instrumentos eléctricos no es igual a hacerla con recursos electrónicos y digitales. Cambiar las posibilidades sonoras. Las innovaciones tecnológicas asociadas a la automatización de los procesos han vuelto tan potente la maquinaria de producción.

\section{Un jazz digno de aceptación}

En esta sección se omiten hasta cierto punto comentarios relativos a los aspectos formales y estéticos de la música; la estética es en todo caso una invención moderna y no tiene que nada con la música y su función reguladora de una sociedad (Attali, 1995). Consideramos entonces, siguiendo la línea frankfurtiana, que "La vida en el capitalismo tardío es un rito permanente de iniciación. Cada uno debe demostrar que se identifica sin residuos con el poder por el que es golpeado. Ello está en la base de las síncopas del jazz, que se burla de las trabas y al mismo tiempo las convierte en normas" (Adorno y Horkheimer, 1988, p. 19).

Ciertamente el jazz es despreciado por Adorno. Encarnaba paradigmáticamente lo que identificó como la música popular de la época. Emerge de la reproducción mecánica en la industria discográfica cuando aparecen los discos que capturan a esos músicos y orquestas que otrora entretenían al pueblo en bailes y espectáculos musicales en vivo. Debemos tener en consideración que en las décadas de 1920 y 1930 fue el momento que la música, fundamentalmente bailable, tocada y producida por la misma 
gente del entorno cercano, cedió su producción a la industria cultural para las masas. Es ese momento cuando la memoria colectiva o, en el mejor de los casos, el capturar la música en papeles con pentagramas y sus respectivas notaciones dejan de ser la única forma de hacer reproducible la música. Junto a los discos aparecieron promotores de conciertos y presentaciones, de igual manera que clubes dedicados a este giro de música en vivo.

El jazz viene a anunciar la entrada a una nueva fase en el desarrollo del modo de producción capitalista. el modelo industrial se perfecciona y vuelve aún más visibles sus contradicciones alimentadas por la correspondencia de las relaciones sociales de producción con las ideologías que le mantienen. La música se vuelve un elemento de complacencia para el auditorio que bajo la apariencia de innovación, encubre "los conceptos reificadores" (Rojas Crotte, 1999, p. 80).

Las anotaciones de Adorno sobre el jazz son severas. Pero también han sido juzgadas severamente. Para algunos están "entre las mayores estupideces de la historia intelectual de occidente [ya que] no se trató de un exabrupto de juventud sino de una constante que delata una incomprensión radical aún más sorprendente, por tratarse de un intelectual y músico a la vez que además estaba inmerso en un entorno de vanguardia y muy permeable a lo nuevo" (Noya et al., 2014). El público del jazz fue descrito por Adorno como falto de juicio musical, lanzando poderosas acusaciones, por ejemplo, que "la preferencia fanática de generaciones de jóvenes por el jazz protesta inconscientemente y proclama la contradicción, porque la producción que se ha adaptado a la industria (o que al menos se comporta como si lo hubiera hecho) va cojeando desamparada, por cuanto respecta a su complexión, tras las fuerzas productivas artísticas, compositivas" (Adorno, 2004, p. 357).

Peter Martin apunta sobre las "fragilidades metodológicas" de Adorno, ya que sus estudios sobre jazz y canciones folk fueron elaboradas sin contacto real con el material y constituyen "descalificaciones apriorísticas en bloque" a pesar de las agudas observaciones sobre el carácter fetichista de la música (Martin, 1995). Si Adorno se equivocaba desde el principio sobre el jazz es porque Adorno no estudió al jazz en sí mismo sino su transformación en "música de entretenimiento" o en todo caso en aquello en lo que se había convertido en el marco de su popularización. Sin aclararlo explícitamente, Adorno estaba refiriendo sólo a la música grabada y no a lo que sucedía con alegría en salones de baile y fiestas. Quizá Adorno mismo fuese consciente de la parcialidad de su análisis dado en sus escritos sobre el jazz insistía en la degradación que había sufrido al alimentar 
la maquinaria de la industria cultural de masas. Si en un principio el jazz pudo ser una forma de expresión auténtica del pueblo negro en los Estados Unidos (y por lo tanto un vehículo de crítica social), al convertirse en música de baile y entretenimiento pasó a ser una nueva herramienta de dominación.

Considerando tal punto de vista, el jazz expresaba la alienación de los negros; los blancos vendrían a robarles esta creatividad engendrada en el trabajo y en las formas elementales de industrialización, para revendérsela a continuación, pues el primer mercado del jazz estuvo constituido por los trabajadores negros de los ghettos de las ciudades del norte. El capital blanco, propietario de todas las firmas de discos, controla desde el comienzo esta comercialización. En este sentido, Adorno sugiere que el jazz "se ha beneficiado de su propia alienación"; ha reflejado muy crudamente la situación de los afroamericanos y su explotación (Attali, 1995, p. 168). Su entrada en el mercado se afirma con el comercio de los rythym \& blues de los ghettos negros del norte de los Estados Unidos, y que se extendió entre las clases medias blancas, gracias al lanzamiento masivo de los discos de 45 revoluciones por minuto (RPM) y a los programas de las estaciones de radio especializadas.

Siguiendo esta lógica el jazz (al igual que el blues y hoy en día el rap) fue para los afroamericanos el refugio de una violencia sin salida política; fue seguido por una implacable recuperación, ideológica y técnica, ya que el mercado fue controlado por empresarios y consumidores mayoritariamente blancos (Jackson, 2012). Como mencionan Megill y Demory (2001), en raras ocasiones se pagaron derechos de autor a los negros que grababan sus cantos. Al artista negro se le pagaba por tocar una pieza y no por la venta de discos, lo que equivale a pagar por insumos en materia prima y no por un el valor agregado a un producto que puede reproducirse tantas veces como se desea.

Otros agentes involucrados en la línea de creación de valor, a partir de entonces, serían los promotores y los dueños de los clubes que ofertaban jazz, y cuyas ganancias son superiores y a costa de los músicos. Hacia la década de los cincuenta las agencias y promotores impulsaron las ejecuciones "de concierto" como una alternativa a los clubes. El jazz llegará además a espacios que no le eran comunes como los festivales (particularmente el de Newport iniciado en 1953) empezará a tomar parte en la oferta educativa de las principales escuelas de música estadounidense; adquiere aceptación como un género "honrado y respetable" y a proclamarse que el jazz es una "forma artística afroamericana" digna, a pesar de haber 
tenido en las tabernuchas y prostíbulos (sic.) sus contextos performativos originarios (Hentoff, 1968, p. 395). Como explica Hentoff (1968, p. 418), la ironía de lo mucho que aconteció en la escena del jazz a mediados del siglo XX es que "los jazzmen comprometieron su música por el dinero, por la figuración y la ilusión de que al llegar a miles de oyentes, ayudan al jazz a abrirse camino para ganar aceptación".

Valdría la pena cuestionar; ¿aceptación de quien en todo caso? ¿Del inexistente público en general? Según Walter Benjamin (2003, p. 21) las nuevas masas "poseen un nuevo tipo de percepción o sensibilidad", y esto trae consigo "la decadencia del aura". En este sentido, los conciertos masivos "no implican simplemente una alteración de la forma concierto propia de la alta cultura sino una destrucción de esa forma" y una sustitución de ella por otra cosa cuya consistencia es difícil de precisar dada su sujeción al negocio del espectáculo (Benjamin, 2003, pp. 21-28). Independientemente de ello, los clubes nocturnos siguen siendo el espacio por excelencia para trabajar tocando jazz, y la mayoría de los jazzmen, incluyendo a "los grandes" (en términos de aceptación por el público) se dejan explotar por las agencias o los dueños de los clubes. Aunque las salas de concierto sean espacios con acústicas mejoradas y posibilidades auditivas, tal contexto performativo no atañe a un discurso a favor del refinamiento artístico. De hecho, los contextos de performance fríos y refinados pareciera que ceden ante los festivales masivos en espacios abiertos patrocinados por las compañías de cerveza. Esta situación revive el cuestionamiento de Hentoff sobre la propiedad última del jazz ¿es de los agentes de contratación, de los promotores de festivales, o de los músicos? (Hentoff, 1968, p. 408).

Ahora bien, no puede negarse el éxito de los conciertos y festivales en términos artísticos y financieros. Pensemos en Erroll Garner, el Modern jazz Quartet, Dave Burbeck, e inclusive Thelonious Monk, quienes sin duda se beneficiaron de su desarrollo expresivo a partir de tal éxito financiero. Sin embargo, el éxito financiero que tales jazzistas pudieron obtener no se basó en la consagración del jazz como forma artística, sino en todo caso de hacer vendible al gran público la estereotípica característica formal del jazz: la improvisación.

La improvisación consiste en un recurso musical que para el caso del jazz requiere de un beat constante con suficiente swing, como para poder "columpiarse" libremente. Por ello las improvisaciones en el jazz caracterizan y brindan una imagen de libertad con la que se identifica a ésta música permite afirmar la continuidad del capitalismo. Aunque la música popular y particularmente los músicos del jazz tengan sus propios mecanismos de 
reconocimiento, los críticos frankfurtianos, puristas al extremo, mencionaban que la improvisación era regida únicamente por la idea de "crear al momento", que "carecía de reflexión creativa", y que "el no repasar y hacer el ejercicio de reflexión ante la pieza limitaba su refinamiento". El nuevo estilo constituye "un sistema de no-cultura, al que se le podría reconocer una cierta 'unidad estilística', si se concede que tiene sentido hablar de una barbarie estilizada" (Horkheimer y Adorno, 1988, p. 5).

Para no escatimar en ejemplos de la dura crítica adorniana en la Dialéctica del iluminismo puede leerse:

[...] eternamente golpea la máquina del jazz, pese a todo progreso de la técnica de la reproducción, de las reglas y de las especialidades, pese a todo agitado afanarse, el alimento que la industria cultural alarga a los hombres sigue siendo la piedra de la estereotipia. La industria cultural vive del ciclo... de que las ruedas continúen girando. Eso sirve para remachar la inmutabilidad de las relaciones (Horkheimer y Adorno, 1988, p. 17).

Así mismo, en su obra Teoría estética, Adorno afirma que:

El esteticismo malo de la política asmática es el complemento del agotamiento de la fuerza estética. Al recomendar el jazz y el rock and roll (en vez de Beethoven)...se proporciona un pretexto a la barbarie y al interés económico de la industria cultural. Las cualidades presuntamente vitales e inmaculadas de esos productos son elaboradas sintéticamente por esas fuerzas a las que presuntamente se refiere la gran negación: ahora esas cualidades si que son manchadas (2004, p. 492).

En fin, para Theodor W. Adorno el jazz ["hijo de la improvisación, de la libertad y de la ruptura"], no es más que la reproducción estereotipada de fórmulas para componer música que operan como si fuesen "recetas fáciles" con las que se puede "encandilar al público" (Hernández Iraizoz, 2013, p. 135).

\section{Nacimiento del rap y el mercado de la irracionalidad}

Según lo escrito por Borneman (1968), en América toda la tradición de la música sincopada popular debió su origen al esclavo negro procedente de África. Ello significó que la música afroamericana se convirtió en parte del 
pueblo y no fue sólo un entretenimiento proporcionado a los auditorios blancos por parte de los músicos y artistas negros. Con la emergencia del rap y la cultura urbana del hip hop a partir de la década de 1980 (y visto a la luz del éxito comercial del trap y reggaeton de hoy en día) se vuelve por demás evidente que las formas musicales africanas nunca han sido destruidas y cada vez más, el éxito comercial del momento requiere de la música negra revitalizada de alguna u otra forma. ${ }^{8}$

Aunque pareciera que, de manera inevitable "se extinguieron todas aquellas canciones y danzas que no eran funcionalmente necesarias según la pauta de las relaciones entre amo y esclavo" (Borneman, 1968, p. 12), las músicas negras nunca han sido un instrumento pasivo a pesar de su plena integración a la industria de la canción comercializada. Cuando el jazz se hubo convertido en un gran negocio, el músico de éxito se encontraba "en una selva similar a la del sobrio territorio de la música pop, aunque el principal medio de sustento fue tocar en los clubes nocturnos de las ciudades, muchos de los cuales tenían acuerdos con las compañías grabadoras" (Hentoff, 1968).

En un momento dado el ritmo del jazz fue contestatario. Fue marginal. Estuvo en espacios que propiciaron el desarrollo de una escena donde músicos negros establecieron una serie de pautas que diferenciaron su manera de hacer música (fórmulas de improvisación a partir de ritmos cadenciosos y sincopados). Además, sus contextos performativos se distinguían sobre aquellos de las orquestas blancas de la época. En estos espacios se normalizó un ambiente asociado a la vida nocturna de la gran ciudad, precisamente porque el mantenimiento total de dichos espacios requería más de la venta de alcohol antes que de entradas en taquilla (Becker, 2004). ${ }^{9}$

El hip hop como movimiento cultural nace a principios de 1980 en los ghettos del Bronx. Decir que comparte con el jazz ciertas caracterizas esenciales es poco. Podemos comenzar con que los ritmos, tanto del jazz como del hip hop tienen sus raíces en la cultura africana; ambos géneros musicales forma parte de una estructura más grande, dado que tanto el

\footnotetext{
${ }^{8} \mathrm{El}$ asunto de las apropiaciones musicales ha sido trabajado desde distintas perspectivas y en distintas latitudes. Se pone a consideración del lector revisar los trabajos de José Jorge Carvalho (2003) así como los ensayos de Charles Keil y Steven Feld (1994), y lo dicho al respecto en la compilación de Georgina Born y David Hesmondhalgh (2000).

${ }^{9}$ Los músicos de jazz y su mundo artístico (mundo de arte) ha sido uno de los principales temas en la sociología del arte y de la desviación del sociólogo norteamericano Howard Becker (2008 y 2009).
} 
jazz como el hip hop tienen una función más allá de la producción sonora y las innovaciones tecnológicas.

Como explica Tricia Rose (1994), el rap es una amalgama impresionante de formaciones musicales complejas más allá de simples extensiones de las tradiciones orales y de las formas expresivas africanas. El rap debe entenderse como "una oralidad secundaria" en una realidad "mediada electrónicamente y coyunturalmente inserta en las relaciones de poder y la política". Sin duda. sus raíces comunes son afroamericanas y están intrincadamente ligadas con zonas urbanas marginadas con una población mayoritariamente negra, donde esta música sirve como catalizador emotivo, representando a la gente que ahí vive y su realidad. El análisis de Rose (1994) sobre la repetición producida a partir de samples y la apropiación de la tecnología digital debilita las perspectivas de Adorno y Benjamin sobre la repetición musical vinculada al sistema del capitalismo tardío de la misma manera que otras formas musicales. Rose (1993; citada en Mclaren, 1998, p. 162) argumentaba que la repetición en las formaciones culturales de masas también podría servir como una forma de resistencia colectiva: la producción del rap convierte en música las prioridades culturales negras en la era de la reproducción digital.

De igual manera, Peter McLaren, pedagogo crítico y heredero del pensamiento frankfurtiano, se refiere a los artistas de rap como "intelectuales orgánicos" (a la manera sugerida por Gramsci), es decir, "trabajadores culturales comprometidos con las luchas diarias de los negros de la clase trabajadora y de los pobres urbanos" (McLaren, 1998, p. 161). Para McLaren "el rap es un idioma negro que da prioridad a la cultura negra y que expresa el problema de la vida urbana de los negros" (p. 161); sirve, como vehículo expresivo para las generaciones negras pobres al no encontrar desahogo para los crueles recuentos de su vida cotidiana.

Sin embargo, así como la esencia, o mejor dicho "el aura" del jazz, al ser grabado perdió, entre otras cosas, el toque de la improvisación, pareciera que el rap se ha convertido en una manera de producir música que poco a poco se ha ido alejando de su esencia, hasta degradarse, al punto donde la venta del producto es la meta. Los avances tecnológicos permitieron su comercialización y reproducción masiva. El hip hop se convierte en un ritmo estandarizado que se fue popularizando y usando indiscriminadamente.

Esta comercialización abarca varios aspectos de la totalidad del producto hip hop: tanto la estética de la música, como la propia estética de la 
parafernalia de los raperos se vuelve un producto reproductible y vendible, y un producto carente de mensaje contestatario en su lírica. En efecto, cuando el rap fue "descubierto" por la industria de la música y la industria de la moda, surgió el estilo conocido como gangsta rap. Para muchos, se trataba simplemente de vender el resentimiento afroamericano mediante con volumen potente. Rápidamente los raperos "gangsta" se convirtieron en uno mas de la larga lista de músicos acusados por los guardianes de la moral estadounidense de ser los instigadores principales de la delincuencia juvenil. Desde entonces el rap (y su enorme gama de estilos) se desarrolló como una expresión relativamente independiente de "la rebelión artística del varón negro contra la burguesía negra” (McLaren, 1998, pp. 153-154); se enfocó en las virtudes y vicios culturales de la negritud como infraclase, dando un cariz de romanticismo al ghetto como la raíz fecunda de la identidad y la autenticidad cultural; expresando explícitamente la violencia, la misoginia y un estilo de vida exagerado y fantasioso, donde la superioridad se traduce a dominación violenta; sobrevalorando posesiones lujosas y costosas, y presumiendo el vínculo al crimen y a la posesión y trasiego de narcóticos.

Walter Benjamin sostuvo que "la autoenajenación llega a tal grado que la humanidad [autoenajenada] se vuelve una espectadora capaz de disfrutar estéticamente su propia aniquilación" (2003, p. 28). La cultura del hiphop se convirtió en la cultura popular urbana del siglo XXI a partir de una relación de ida y vuelta "del mainstream a la periferia", tenido en la "cibercultura" y el "isomorfismo expresivo" sus más potentes mecanismos de mediación (Janotti y de Olivera, 2018).

Indudablemente, pocas manifestaciones dentro de la cultura popular han sido más fuertes y políticamente más poderosas que el rap gangsta, quizá el movimiento ofensivo cultural y político más fuerte entre los afroamericanos. El rap gangsta es la expresión de una patología social implacable, de la pandilla como forma de vida, de "una conciencia potencial de oposición nacida de la desesperación” (McLaren, 1998, pp. 160 y 166), y produce la experiencia de "choque" con la que Benjamin caracteriza la vida entre multitudes urbanas modernas. ${ }^{10}$ Ante esto McLaren se cuestiona:

¿Puede el rap gangsta ir más allá de los efectos de choque de Benjamin, su decontextualización como efecto de su reproductibilidad mecánica,

\footnotetext{
${ }^{10}$ Para Benjamin el choque (shock) es la esencia misma de la experiencia moderna. Guido Vespucci (2010) brinda un aporte ampliado sobre las implicaciones de este término en la obra de Walter Benjamin.
} 
más allá del espacio de sus propias estructuras comerciales. más allá de sus prohibiciones ideológicas, sus estructuras de expectación, sus demarcaciones de desesperación, todo lo cual crea una situación de fantasmas significantes y formas perversas del 'otro', el cual a su vez, colabora con los enfoques neoliberales de la política que en el fondo le quitan al rap su fuerza de oposición? (1998, p. 187).

De cualquier manera el rap gangsta, aún habiendo generado una escena en las urbes del globo entero, ha pasado de moda; aun cuando "la condición ontológica del rapero gangsta" resida en función de la mercantilización de la negritud (McLaren, 1998, p. 175), el rap contemporáneo difiere de su manifestación original al ser algo totalmente vendible, consumible, dado a que ya está siendo producido bajo el encargo de la lógica de mercado. La originalidad del ghetto se convirtió en piezas de parafernalia producidas en serie y son objetos totalmente reemplazables, adquiribles e identificables bajo la lógica de consumo. ${ }^{11}$ Peor aún, la reproducción incesante de las apropiaciones del rap en contextos periféricos reniegan de la obligación de representar algo o a alguien (al barrio, a la pandilla, al crew, etc.) que recaía en los rappers y en los $M C^{\prime}$ 's. Como botón de muestra, en el tema "Trap life", Kidd Keo, tropicalizando la tendencia, se auto-afirma: "Yo no soy un gangster, yo no soy un guerrillero/A mí me gusta vacila' con mi cara 'e niño bueno". 12

Retomando a Benjamin (2003), la estetización del mundo no se cumple hoy en día "a través de una formalización de la producción espontánea de arte bajo la acción de las Bellas Artes". La producción artística "resulta del cultivo salvaje de las formas de la vida cotidiana", dentro de las posibilidades realmente existentes. 0 sea, "dentro de un marco de acción manipulado directamente por la industria cultural y su encargo ideológico". La estética del rap gangsta nos remite forzosamente a una política de identidad que ha de ubicarse en el marco de la globalización del capital financiero, los circuitos internacionales de deuda y de consumo, la desindustrialización, la desindicalización del trabajo en el sector terciario y la crisis del sistema escolar capitalista.

\footnotetext{
${ }^{11}$ Ejemplos de esta nueva generación de rap bajo la lógica de mercado destacan artistas como: ‘Lil pump, 'Lil yachty, 6ix9ine, 'Lil xan, 'Lil peep, 'Lil windex, entre otros. Todos estos artistas comparten varios elementos tanto en su estética personal, las características formales de su música (llamado trap) y las letras de sus canciones. Los visuales representados dentro de sus videos musicales se han reproducido en otras latitudes del globo.

${ }^{12}$ Recuperado de https://youtu.be/N9qI2ywwIYM?t=207
} 
Finalmente para adentrarse en la comprensión de esta manifestación que se ha vuelto global, es necesario escuchar al rap (y hoy en día trap, el estilo en boga) no sólo como una formación ideológica, como un significante cultural, o una práctica performativa, sino también como el producto de relaciones históricas y sociales expresadas en el plano discursivo y, sobre todo, en términos de la materialidad de tal discurso. ${ }^{13}$

\section{Conclusiones}

En este trabajo se ha tratado de hacer notar que desde la óptica de la escuela de Frankfurt, la comprensión de la relación música-sociedad debe entenderse como una relación establecida en términos de comerciales. En este sentido, la cooptación de movimientos musicales contestatarios por parte de la industria musical, bajo la lógica de mercado, tiene como base la cada vez más inmediata reproducción musical basada en la tecnología de reproducción masiva a través de medios digitales. Esto es, la industria y sus agentes trasforman la música que se ejecuta en vivo, como un medio de expresión sobre la realidad vivida, lo trasforma en un producto de consumo y desecho inmediato, donde los artistas asumen un papel, un rol vendible, fantasioso, que alude en su mayoría a valores del mercado musical capitalista.

Bolívar Echeverría señaló que para Benjamin “la reproducción técnica de la obra de arte es un factor que acelera el desgaste y la decadencia de la obra" (Echeverría, 2003, p. 17). ¿Qué podemos decir entonces cuando el sampleo se ha vuelto la actividad artística no sólo de vanguardia, sino la más común y corriente? Hoy en día hacer música consiste en juntar fragmentos de otras obras, a veces reconocibles y a veces no, en una nueva creación que sólo puede tener lugar en la era de la reproducción digital. La reproducción digital permite re usar una obra de culto y al mismo tiempo integrarle a la lógica del disfrute cotidiano.

En la sociedad de la información y con el acceso a cualquier banco sonoro la composición y la identificación con los géneros musicales que acabamos de atender son quizá una breve muestra de que se puede componer y disfrutar de músicas de manera paralela a producción comercial. Existe también una producción por encima de aquellas creada para alimentar la

\footnotetext{
${ }^{13}$ La expresión materialidad del discurso refiere a "las formas como la cultura construye subjetividades, reproduce relaciones de poder y fomenta la resistencia", en la medida en que estas relaciones y prácticas son "moldeadas por las totalidades sociales como el capitalismo, el patriarcado y el imperialismo, puesto que estas se manifiestan de diferente manera a través de transformaciones sociales y dentro de coyunturas históricas específicas" (McLaren, 1998, p. 184).
} 
necesidad de expresión de las minorías en las ciudades del mundo global. ¿Nos habla esto de arte musical para una sociedad emancipada? Según Bolívar Echeverría:

[...] el fundamento de la tendencia anti aurática en el arte contemporáneo hay que buscarla en la resistencia y en la rebelión de las masas contemporáneas frente al estado de enajenación al que su subjetividad política se encuentra condenada en la modernidad capitalista y consolidarse como una transformación postcapitalista de la vida social (2003, p. 20).

Podríamos convenir que con el advenimiento del jazz se popularizó la improvisación (como repetición inventiva) y se legitimó la comercialización de un nuevo modo de participación en la experiencia estética musical basada en la cercanía con el objeto. Sin embargo, con el advenimiento del rap pareciera que las masas que tienden a menospreciar la singularidad irrepetible y a valorar la obra reactualizable (por ejemplo en los remixes). El nuevo arte impone la creación a partir de un nuevo sistema de aparatos, otrora los instrumentos, hoy los sintetizadores y el sampler.

Constantemente tiene que aparecer un ritmo contestatario que se integre a la lógica del mercado para revivirlo. Siempre tiene que ser algo cada vez más provocativo, y más difícil de imitar. Curiosamente, lo que representó el jazz para los años 1930 y 1940, la difusión de los discos en el mundo entero y sobre todo el impacto que tuvo, podríamos considerarlo como algo muy cercano lo que está pasando con el rap. Ahora todo el mundo está usando sampleos y ritmos sintetizados como base, y la métrica del rap para componer. Esta lógica formal empieza a determinar la manera en la que todo el mundo está haciendo la música, y así será hasta que surja otro ritmo, más contestatario, que renueve la industria musical como este trato constante entre la nueva música contestataria y su inevitable reificación en función del mercado.

Sin embargo, en estos mismos movimientos pueden encontrarse voces alternativas, que quizá tachadas de subversivas por no integrarse a la lógica del mercado, mantienen un estatus artístico aún cubierto por esa aura que distingue a las obras, que según Benjamin, tiende a desaparecer. Y no es que el aura de las obras desaparezca sino que se traslada a otro lugar, a otro espacio. El disco se ha vuelto un fetiche en una era donde todo circula por Internet, y donde los artistas, por muy buenos que sean, pasan al olvido rápidamente. 


\section{Bibliografía}

" Adorno, T. W. (2004). Teoría estética. Madrid: Akal.

"Adorno, T. W. (2008). Escritos Musicales IV. Madrid: Akal.

"Adorno, T. W. (2009). Sobre el carácter fetichista de la música y la regresión de la escucha. En Disonancias. Introducción a la sociología de la música (pp. 15-50). Madrid: Akal.

" Agawu, K. (1995). The Invention of African Rhythm. Journal of the American Musicological Society, 48. Recuperado de http://www.jstor.org/ stable/3519832

»Alexander, J. C. (1989). Las teorías sociológicas desde la segunda guerra mundial. Barcelona: Gedisa.

»Attali, J. (1995). Ruidos. Ensayo sobre la economía política de la música. México: Siglo XXI Editores.

» Bártok, B. (1997). Escritos sobre música popular. (5ta ed.). México: Siglo XXI Editores.

» Becker, H. S. (2004). Jazz Scene. En A. Bennet y R. Peterson (Eds.) Music Scenes. Local, Translocal and Virtual (pp. 17-30). Nashville: Vanderbilt University Press.

» Becker, H. S. (2008). Los mundos del arte: sociología del trabajo artístico. Buenos Aires: Siglo XXI Editores.

» Becker, H. S. (2009). Outsiders. Hacia una sociología de la desviación. Buenos Aires: Siglo XXI Editores.

" Benjamin, W. (2003). La obra de arte en la era de su reproductibilidad técnica. México: Ítaca.

" Born, G. y Hesmondhalgh, D. (2000). Western Music and its Others. Los Angeles: University of California Press.

» Borneman, E. (1968). Las raíces del jazz. En N. Hentoff y A. J. Mc Carthy (Eds.). Jazz, psicología y sociología (pp. 11-41). Buenos Aires: Paidos.

»Bottomore, T. (1983). A Dictionary of Marxist Thougt. New Jersey: Blackwell Publishing Ltd.

» Bourdieu, P. (2000). La distinción. Criterio y bases sociales del gusto. Madrid: Taurus.

» Bourdieu, P. (1990). Origen y evolución de las especies de melómanos. En Sociología de la Cultura (pp. 127-133). México: CONACULTA.

»Carvalho, J. J. (2003). La etnomusicología en tiempos de canibalismo musical. Una reflexión a partir de las tradiciones musicales afroamericanas. Trans. Revista Transcultural de Música, 7.

»Echeverría, B. (2003). Introducción: Arte y utopía. En Benjamin, W. La obra de arte en la era de su reproductibilidad técnica. México: Ítaca. 
» Feld, S. (1994). From Schizophonia to Schizmogenesis. En Ch. Keil y S. Feld (Eds.). Music Grooves (pp. 257-289). Chicago and London: The University of Chicago Press.

» Giner, S. (2008). Historia del pensamiento social. (12a ed.). España: Ariel.

»Hentoff, N. (1968). ¿De quién es la forma artística? El jazz a mediados de siglo. En N. Hentoff y A. J. McCarthty (Eds.). Jazz, psicología y sociología (pp. 394-418). Buenos Aires: Paidos.

»Hernández Iraizoz, D. (2013). Theodor Adorno, elementos para una sociología de la música. Sociológica, 28(80): 123-54. Recuperado de http:// www.sociologicamexico.azc.uam.mx/index.php/Sociologica/article/ view/31/26.

»Horkheimer, M. y Adorno, T. W. (1988). La industria cultural. Iluminismo como mistificación de masas. En M. Horkheimer y T. W Adorno. Dialéctica del iluminismo (pp. 1-26). Buenos Aires: Sudamericana.

» Jackson, T. A. (2012). Blowin' The Blues Away. Performance and Meaning on the New York Jazz Scene. Los Angeles: University of California Press.

» Janotti, J. J. y de Olivera e Silva, R. (2018). Nem original, nem cópia: versões musicais entre o mainstream e a periferia. Resonancias, 21(41), 145-62. Doi: https://doi.org/10.7764/res.2017.41.7

»Keil, Ch., y Feld, S. (1994). Music Grooves. Chicago and London: The University of Chicago Press.

» Marcuse, H. (1968). El hombre unidimensional. Madrid: Ed. Crítica.

»Martin, P. J. (1995). Sounds and Society. Manchester and New York: Manchester University Press.

» Mattelart, A. (1974). La cultura como empresa multinacional. México: Ediciones Era.

» McLaren, P. (1998). Pedagogía gangsta y ghetocentrismo: la nación hiphop como esfera contrapública. En Multiculturalismo revolucionario (pp. 154-92). México: Siglo XXI Editores.

»Megill, D. y Demory, R. S. (2001). Introduction to Jazz History. (5ta ed.). New Jersey: Pearson Education.

» Negus, K. (1997). Popular Music in Theory. Gran Bretaña: Wesleyan University Press.

» Noya, J., Del Val, F. y Muntanyola, D. (2014). Paradigmas y enfoques teóricos en la sociología de la música. Revista Internacional de Sociología, 72(3):

541-62. Recuperado de http://revintsociologia.revistas.csic.es/index.php/ revintsociologia/article/view/591/614.

» Reich, W. (1973). La psicología de masas del fascismo. México: ROCA.

» Rojas Crotte, I. R. (1999). Theodor W. Adorno y la Escuela de Frankfurt. Convergencia. Revista de Ciencias Sociales, 6(19). Recuperado de http://www. redalyc.org/html/105/10501904/.

» Rose, T. (1994). Black Noise. Rap Music and Black Culture in Contemporary 
America. Connecticut: Wesleyan University Press.

»Sammartino, F. (2008). Benjamin y la difusión radiofónica de la música popular. Ensayos. Historia y teoría del arte, 14, 132-147.

»Vespucci, G. (2010). Despertar del sueño: Walter Benjamin y el problema del shock. Tabula Rasa, 13, 253-72. Recuperado de http://www.scielo.org.co/ scielo.php?script=sci_arttext\&pid=S1794-24892010000200011.

»Yúdice, G. (2007). Nuevas tecnologías, música y experiencia. Barcelona: Gedisa.

\section{Biografía / Biografia / Biography}

\section{Igael González Sánchez}

Nació en Hermosillo, Sonora, en 1981. Obtuvo el grado de Doctor en Arte y Cultura por el Centro Universitario de Arte Arquitectura y Diseño de la Universidad de Guadalajara. Cursó la maestría en Estudios Socioculturales en El Colegio de la Frontera Norte, Tijuana. Candidato a Investigador Nacional del CONACyT, México. Ha realizado estancias de investigación en la Fonoteca del INAH. Ha participado en varias publicaciones colectivas sobre la música Norteña y la música de banda sinaloense. Colaborador en distintos proyectos educativos y comunitarios, así como con artistas y colectivos artísticos de las ciudades fronterizas de Tijuana y Nogales. Actualmente se desempeña como profesor investigador en el programa de la Maestría en Práctica Docente e Integración Cultural de la Universidad Pedagógica Nacional, Unidad Tijuana. 